\title{
SOCIAL MEDIA/NETWORKING: APPLICATIONS, TECHNOLOGIES, THEORIES
}

Somayya Madakam ${ }^{1}$ http://orcid.org/0000-0001-6708-2061

Siddharth Tripathi ${ }^{2}$ http://orcid.org/0000-0002-9871-6706

${ }^{1}$ Information Technology, FORE School of Management, New Delhi, India

${ }^{2}$ IT \& Marketing, Amity Business School, Amity University, Mumbai, India

\begin{abstract}
Nowadays, Social Media communication has become indispensable for the world. Social Media is indeed a paradigm shift in communication. The beauty of this new communication method is the offer of virtual connectivity irrespective of geographical distances. The medium serves us pictures, rich textual content, videos, and audio 24/7 online. Given its wide usage, it is highly crucial to study key details of social media, including the pioneers, theories, and business applications. This manuscript has relied on the "Web of Science" database and the Vantage Point 9 text-mining tool, with Aduna map visualization, to collate about 50 research articles published during 2008-2016 that have studied social media in detail. The objective of this article is to explain the impact of social media sites, technologies, and applications.
\end{abstract}

Keywords: Social Media, Social Networking, Social Media Marketing, Web 2.0, Blogs, Facebook, LinkedIn, Twitter, Instagram, Google+, YouTube, Branding.

\section{INTRODUCTION}

Communication with the external environment starts at an early stage, even before a baby learns to talk. Effective communication can be considered the key to survival. The most fundamental medium of communication is the conversation in one's mother tongue to express their feelings, fulfill their needs, and protect themselves from harm. Gradually, one may learn diverse secondary languages to communicate with the society, based on their upbringing and educational background. Modes of spoken and written communication can carry different messages for various purposes, from the emotional to the commercial. Several languages and methods of communication have evolved in the world. The year 1996 heralded the age of digital communication systems. The world became capable of interacting globally via Internet messages, which gradually evolved from simple text messages to well-designed and speedy multi-media exchange. Today's advanced new technologies like the Internet of Things (IoT), high-speed bandwidth (Petabytes per seconds), big data analytics, data centers, and

Manuscript first received: 2020/09/26. Manuscript accepted: 2021/03/11

Address for correspondence:

Somayya Madakam, Information Technology, FORE School of Management, Qutub Institutional Area, New Delhi - 110016.

E-mail: somayya@fsm.ac.in

Siddharth Tripathi, IT \& Marketing, Amity Business School, Amity University, Mumbai, Maharashtra - 410206.

E-mail: stripathi@mum.amity.edu 
personal digital/smart devices have completely changed the way we are communicating. This modern communication method has been named "Social Media," in which anybody can create an individual account, keep personal details, professional resumes, upload interesting videos, movies, games, and interact with others based on social group interest, connectivity, features, and activities to name a few.

\section{LITERATURE}

The concepts behind social networking are not radically novel - ever since there have been humans, we have been looking for ways to connect, network, and communicate with one another. However, these efforts have taken on an entirely new meaning and momentum in the digital age. Where we used to have handshakes, word-of-mouth referrals, and stamped letters, today's relationships are often begun and developed on LinkedIn, Google +, and Facebook (Milanovic, 2015). A large body of literature has already focused on various aspects of social media. The 'honeycomb framework' by Kietzmann et al. (2011), 'social media metrics framework and guidelines' by Peters et al. (2013), and 'seven layers of social media analytics' by Khan, G. F. (2015) are notable research outcomes that provide the much-needed theoretical rigor. Despite the recent increase in the adoption and use of social media tools to support firm operations, very little empirical research focusing on the impact of social media on small-and-medium-sized enterprises (SMEs) has been conducted to date. A considerable amount of research is available to understand how business organizations are using social networks to achieve branding goals. One specific way to do this is to create brand fan pages on social networking sites. Positive social media marketing messages increase online shoppers' hedonic values. In recent years, numerous articles have been written about the characteristics and topographies of social media (Bulut, \& Mandaric, 2012; DesAutels, 2011; Chapman, 2011; Kaplan \& Haenlein, 2010; Wattal et al. 2010; Mangold \& Faulds, 2009; Trusov et al., 2009; Boyd \& Ellison, 2007). Until 28/8/2017, the Web of Science databases showed up around 44767 articles relating to social media. The database category analysis yielded the information that the top 25 research disciplines were Computer Science and Information Systems, Communication, Computer Science and Theory Methods, Education \& Educational Research, Engineering Electrical Electronic, Business, Information Science \& Library Science, Management, Computer Science \& Artificial Intelligence, Public Environmental \& Occupational Health, Social Sciences \& Interdisciplinary, Computer Science \& Interdisciplinary Applications, Sociology, Psychology Multidisciplinary, Computer Science Software Engineering Economics, Telecommunications, Psychology Experimental, Health Care Sciences Services, Political Science, Psychiatry, Environmental Studies, Multidisciplinary Sciences \& Psychology Social. It indicates that social media is an interdisciplinary subject. Its applications are enormous, regardless of the topic or the research area. Data also reveals that social media is a multidisciplinary subject. Its applications are immense, irrespective of the subject or the research area. However, Computer Science \& Information Systems showed the highest hits due to social media being a technologyoriginated phenomenon. Table 1 in the next page highlights the same.

From Graph 1 (Spider Net), these authors could ascertain that from 2008 to 2016, and out of the 44767 articles, Kim J. had the highest number of publications (67) on social media/networkingrelated articles. Liu Y (60), Zhang Y (58), Anonymous (57), Liu H (55), Lee S (53), Wang Y (53), and Kim Y (49) followed. Among the top 25 authors, Zhang H stood last with 32 articles.

The Web of Science database analysis also yielded the information that in the 2008-2016 period, 2016 had the highest number of publications with 11072 articles, followed by 2015 (9341), 2014 
Table 1. Web of Science Category-wise top 25 Disciplines

\begin{tabular}{|c|c|c|}
\hline S. No & Web of Science Categories & $\begin{array}{c}\text { Total Articles } \\
\quad \text { (44767) }\end{array}$ \\
\hline 1 & Computer Science Information Systems & 4870 \\
\hline 2 & Communication & 4865 \\
\hline 3 & Computer Science Theory Methods & 3891 \\
\hline 4 & Education Educational Research & 3287 \\
\hline 5 & Engineering Electrical Electronic & 2862 \\
\hline 6 & Business & 2847 \\
\hline 7 & Information Science Library Science & 2323 \\
\hline 8 & Management & 2173 \\
\hline 9 & Computer Science Artificial Intelligence & 2020 \\
\hline 10 & Public Environmental Occupational Health & 2010 \\
\hline 11 & Social Sciences Interdisciplinary & 1869 \\
\hline 12 & $\begin{array}{c}\text { Computer Science Interdisciplinary } \\
\text { Applications }\end{array}$ & 1842 \\
\hline 13 & Sociology & 1816 \\
\hline 14 & Psychology Multidisciplinary & 1644 \\
\hline 15 & Computer Science Software Engineering & 1158 \\
\hline 16 & Economics & 1001 \\
\hline 17 & Telecommunications & 954 \\
\hline 18 & Psychology Experimental & 878 \\
\hline 19 & Health Care Sciences Services & 847 \\
\hline 20 & Political Science & 829 \\
\hline 21 & Psychiatry & 821 \\
\hline 22 & Environmental Studies & 702 \\
\hline 23 & Multidisciplinary Sciences & 699 \\
\hline 24 & Psychology Social & 676 \\
\hline 25 & Hospitality Leisure Sport Tourism & 671 \\
\hline
\end{tabular}

(6108). The analysis ascertained that from 2008 onwards, the number of published articles drastically increased, indicating the growth in the importance of social media. This can be viewed in Graph 2.

Graph 3. denotes the countries with the number of research publications on social media. The country with the highest number of publications is the USA (14317), which is followed by England (4293), China (3564), Australia (2802), Canada (2110), Spain (2033), Germany (2020), Italy (1247), Netherlands (1228), India (1121), S. Korea (908), France (900), Taiwan (727), Romania (725), Sweden (722), Brazil (717), Turkey (648) and Japan (592); the top 25.

Webb \& Roberts, (2016) detailed, "Millions of posts, tweets, updates, videos, photos, and pins are initiated, shared, and monitored daily through social media. "Although research related to social media is widespread, there is a definite need for additional research related to selecting social media sites, updating and monitoring of social networks, as well as determining the perceptions or 'rewards' gained by utilizing social media sites in small businesses." In this light, these authors randomly selected 50 research articles published during 2008-2016 from the Google Scholar database and used the same for a detailed literature review. The Vantage Point text mining software was used for prominent keyword analysis by considering the articles' titles, abstracts, and keywords. Vantage 


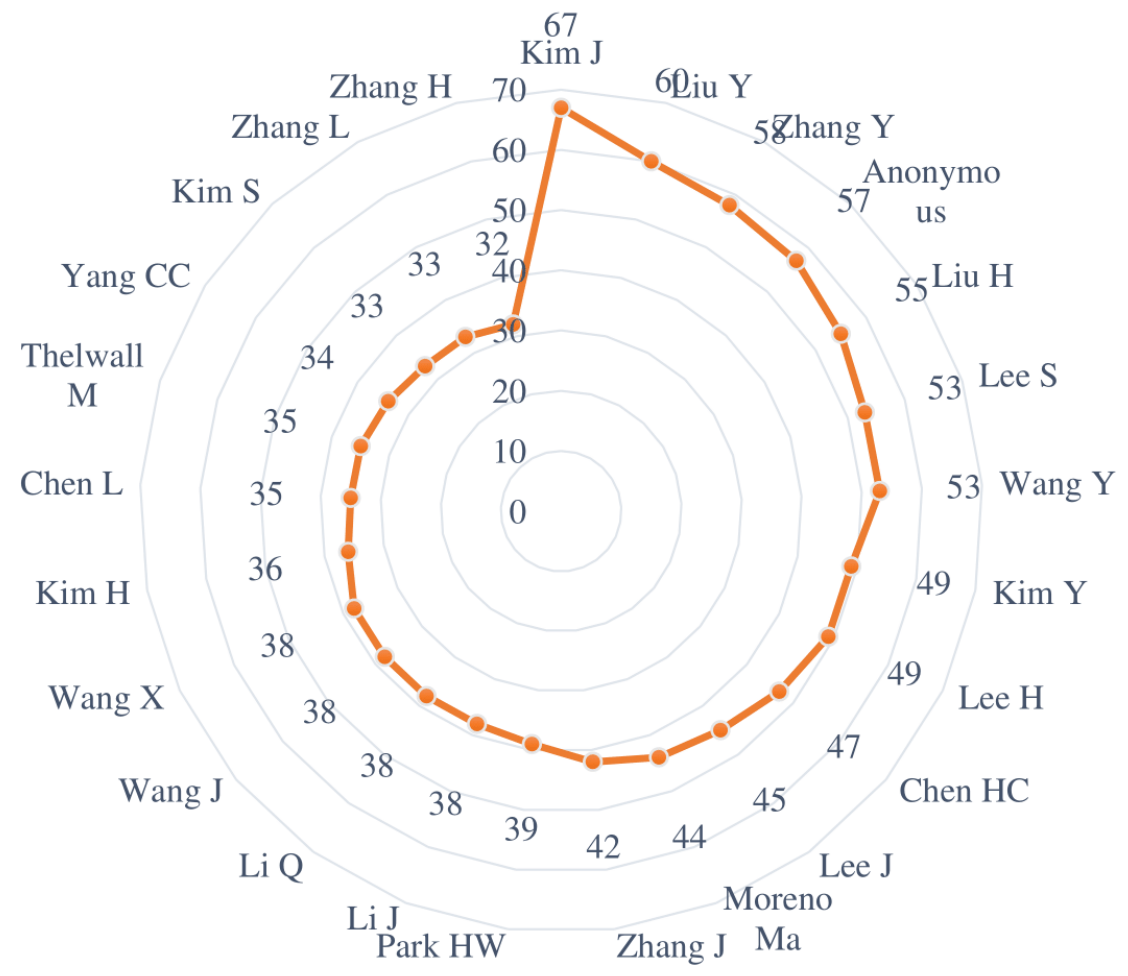

Graph 1. Author wise - Publications

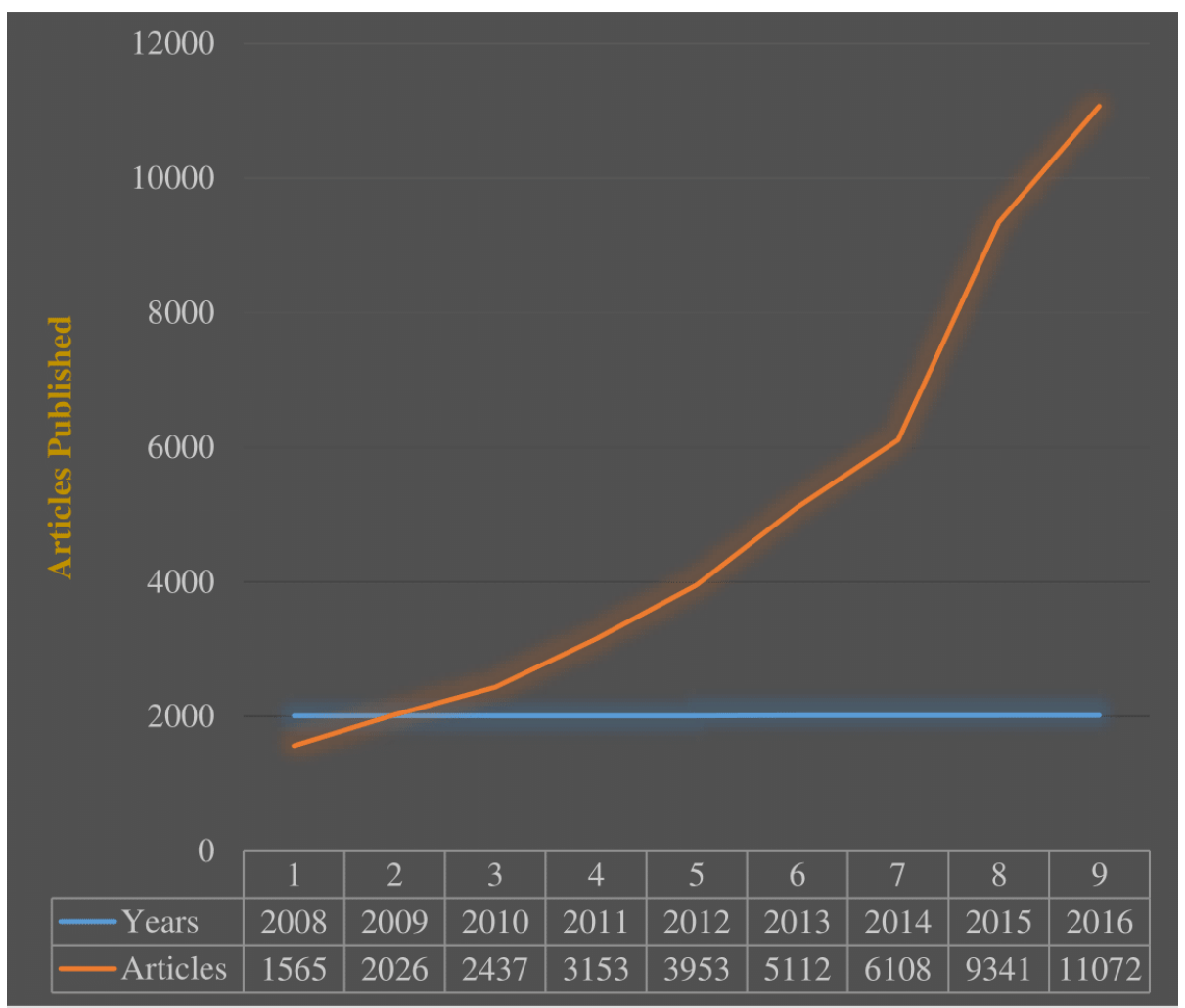

Graph 2. Year-wise - Publications 


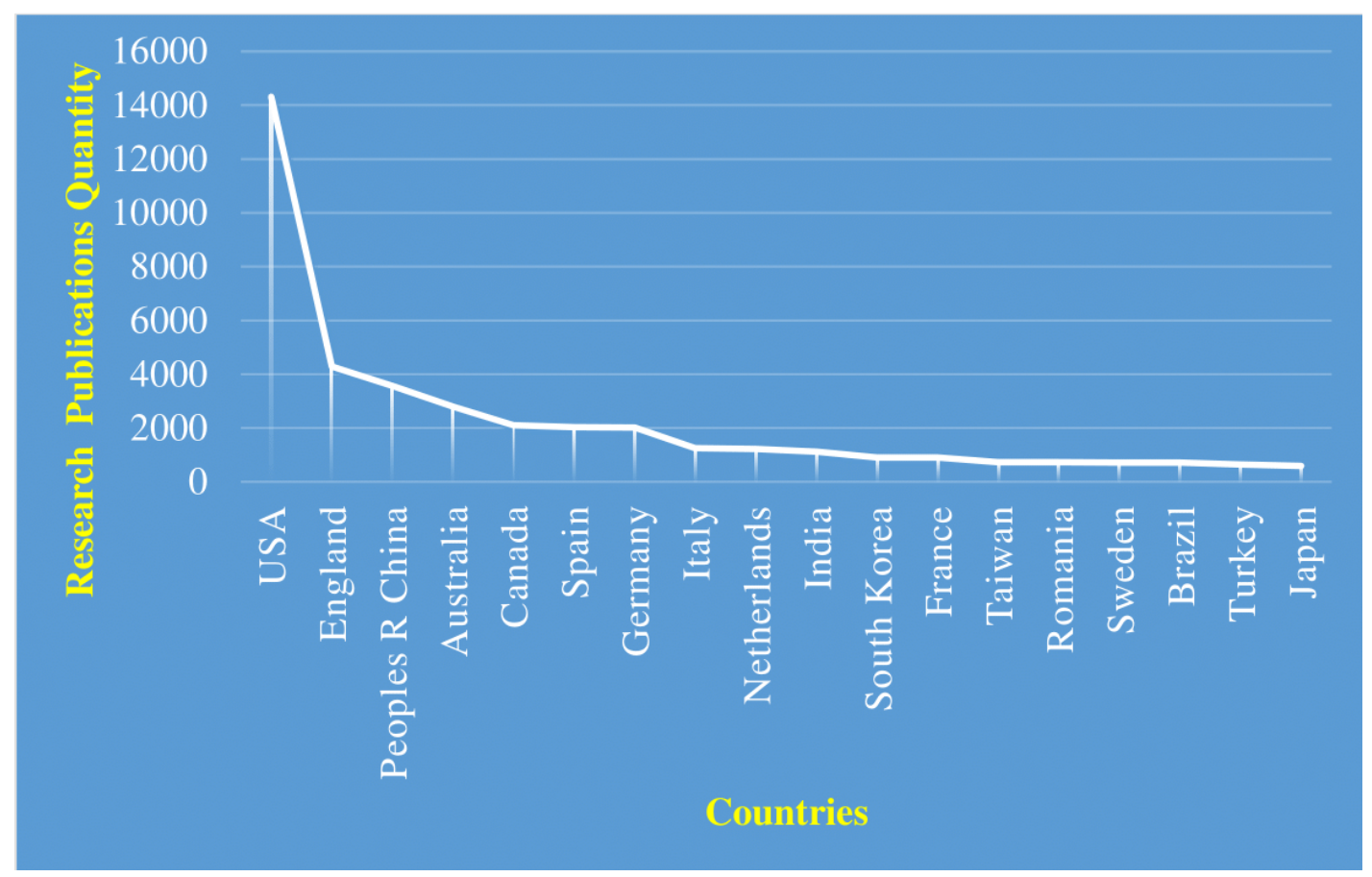

Graph 3. Country wise - Publications

Point is the text mining methodology that employs natural language processing (Samant \& Sangle, 2016). The Vantage Point analysis was conducted for 100 - Keywords after cleaning actual data of 150 author keywords. Some of them are deleted in the cleaning process, and some are merged with others because of similarity. The keyword 'social media' stood first with 27 frequencies, followed by social media marketing (10). Below are the main keywords (with their frequency counts in the bracket) used in research articles. Social Media (27), Social Media Marketing (10), Marketing (9), Web 2.0 (8), Social Networks (6), Blogs (6), Twitter (4), Communications (4), Social (4), Facebook (3), Brand Equity (3), Marketing Communications (3), Activities (2), Content (2), Credibility (2), Customer Equity (2) Customer Relationship Management (2), Internet Marketing (2), Luxury Brands (2), Promotion (2), Purchase Intention (2), Social Networking Sites (2), Traditional Media (2), Travel 2.0 (2), User-Generated (2), Word-of-Mouth (2), Relationship Equity (2), Consumer Engagement (2), e-WOM (2), New Media (2), Urban Emergency Events (2), B2B Brands (1), Brand Awareness (1), Brand Capital (1), Brand Communities (1), Brand Management (1), Budget Spending (1), Buyer-Seller Relationships (1), Buying Decision (1), Communities (1), Competitive Advantage (1), Consumer Behavior (1), Consumer Reviews (1), Consumer-Generated Media (1), Corporate Branding (1), Corporate Communications (1), Customer Orientation (1), Customer Satisfaction (1), Destination Marketing (1), Digital Marketing (1), Direct Marketing (1), E-Shopping Behavior (1), Emotional Bonds (1), Firm-Generated Content (1), Integrated Marketing (1), Internet (1), LinkedIn (1), Marketing Effectiveness (1), Marketing Metrics (1), Marketing Strategy (1), Message Diffusion (1), Modeling Online Activities (1), Online Community (1), Online Consumer Behavior (1), Online Eco Systems (1), Online Marketing (1), Online Segmentation (1), Online Social Media (1), Online Social Networks (1), Online Tourism Domain (1), Participatory Sensing (1), Persuasive Messages (1), PR 2.0 (1), Promotion Mix (1), Public Relations (1), Relational Capital (1), Relational Exchange (1), Relationship Marketing (1), RoI (1), Search Engine (1), Social Advertising (1), Social Capital 


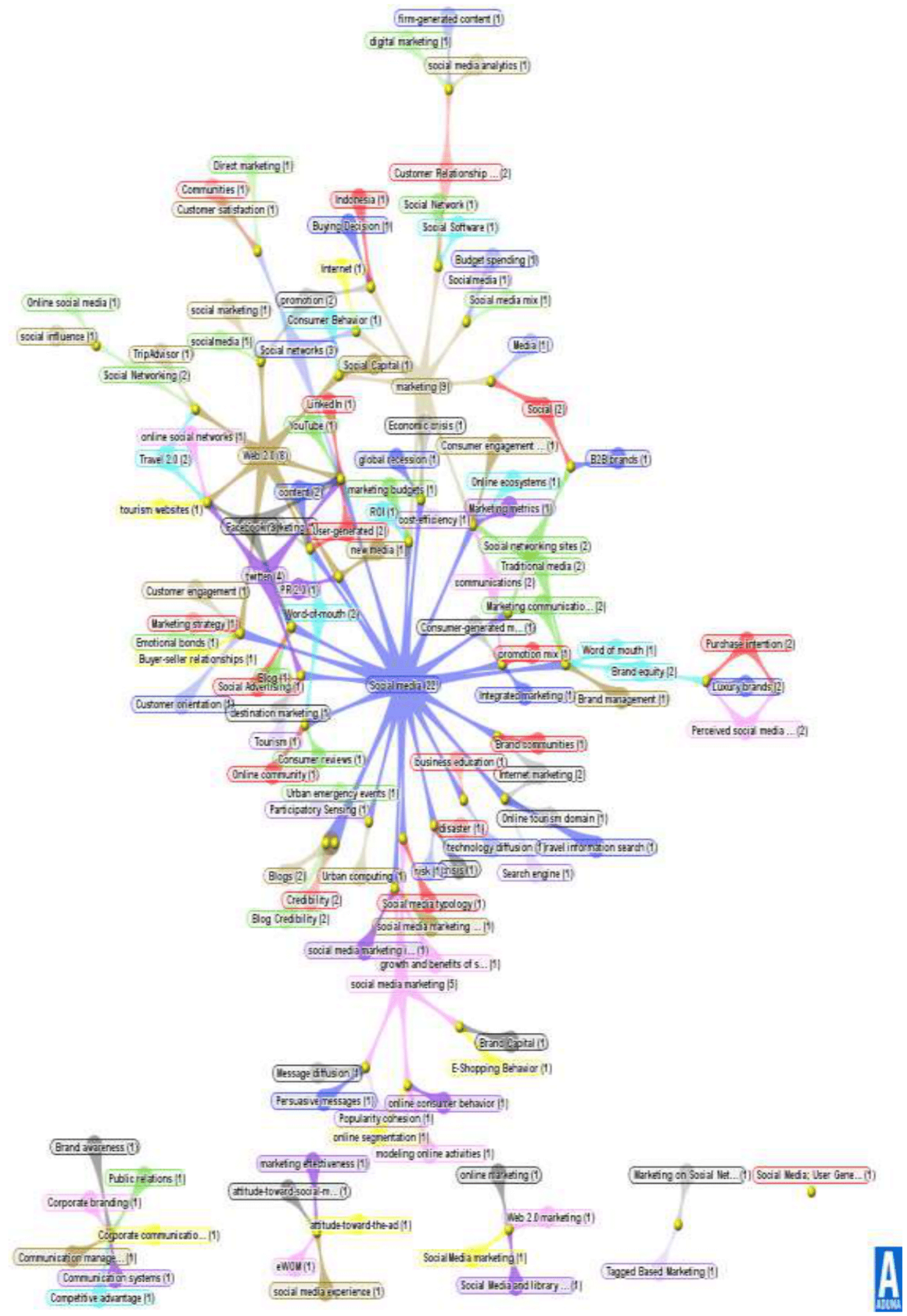

Figure 1. Aduna Map for Vital Keywords 
(1), Social Influence (1), Social Media Analytics (1), Library Marketing (1), Social Media Experience (1), Social Media Marketing Strategy (1), Social Media Mix (1), Social Media Typology (1), User Generated Content (1), Social Software (1), Tagged Based Marketing (1), Tourism (1), Trip Advisor (1), Tourism Websites (1), Travel Information Search (1), Viral Marketing (1), Web 2.0 Marketing (1) and YouTube (1). These are the prime keywords.

The keyword analysis clarifies that social media is the new communication method (digital marketing) in Web 2.0, in which the entire message can be managed through online blogging. Facebook, YouTube, and LinkedIn are some of the well-known social media sites. Several companies prefer to carry out their business online. The best application of social media is the marketing and branding of a company's products, besides consumer networking and transparency of consumer feedback. Another practical application of social media or social networking sites is for the tourism industry to advise and use social software analytics.

\section{METHODOLOGY}

In this paper, the authors intend to clarify "social media" or "social networking" literature. In addition, it is aimed to make a note on vital social media notions and their business applications. Research articles were collated using the Web of Science. The authors used the secondary (online) data and then followed it up by using thematic narration. The research articles were fetched from the Web of Science, Google Scholar, EBSCO, and KNIMBUS databases from 1-4-2017 to 31-8-2017. Research articles published between 2008-2016 were used to review and rewrite the key points on "Social Media/Networking." In toto, 50 articles were chosen randomly using the keywords "Social Media" and "Social Networking." The analytical tools used were the VantagePoint software for keywords of "aduna map" and Microsoft -2013 Excel for the graph generation. Such an in-depth literature review is likely to help budding researchers get guidance on social media and allied subjects, apart from imparting an academic perspective to social media /networking concepts and theories. The future of social media is exceptionally dynamic and likely to undergo massive shape-shift.

\section{SOCIAL MEDIA: NOTIONS}

Social media is always a function of the technology, culture, and government of a particular country. The Social Media phenomenon has been interchangeably referred to as Social Media Networking (Boyd \& Ellison, 2007); Social Networking (Trusov et al., 2009); Web 2.0 (Wattal et al., 2010); and User Generated Information Systems (Desautels, 2011). Social media helps connect people themselves with social networking sites through which they can stay far and yet remain connected. Social media continues to transform contemporary society. Social media has fostered communication, creativity, social cohesion, and advanced freedom of expression. Social media has become a part of our daily lives that enables us to express our views and ideas in a novel way. Due to the advanced features of social media, organizations are adopting social media to improve their business performance (Tripathi \& Verma, 2017). The first distinguishable social media site "Six Degrees," was created back in 1997. It enabled users to create a profile, make friends with other users and upload personal data. The past two decades has witnessed the popularity of blogs and social media that continues today and even in future. 
The sudden growth of community websites such as Twitter, Facebook, and LinkedIn have ushered the world into a new era of social media. Interactive Social Media platforms such as Facebook, LinkedIn, Twitter, YouTube, Foursquare, and Digg in, etc., have radically changed the communication paradigm. Considering the member count on social networks, if Facebook represents a country, it would be the third-largest nation, after China and India in the globe. Nowadays, Online Social Networking (OSN) websites are popular and have become a part of our lives. These sites have made a significant impact on an individual's life. Social networks allow users to communicate, share knowledge about similar interests, discuss favorite topics, review and rate products/services. Online Social Media (OSM) websites have attracted millions of users by enabling them to interact in ways that were not possible before. OSN sites are the most popular sites on the internet. OSN evolved into a global mainstream medium that generated increasing social and economic impact. Social media is the medium to socialize. In reality, Social media and traditional mainstream media both complement each other. As individual public members now are optimistic about having substantial interactions with organizations, especially by using digital media, communication professionals have been looking for ways to enhance these interactions. Widespread discussion of interactive social media and social networks is enabled by what is termed Web 2.0. Web 2.0 applications can directly engage consumers in the creative process by producing and distributing information through collaborative writing, content sharing, social networking, social bookmarking, and syndication. The advent of the Internet and, in particular, the interactive features of Web 2.0 in recent years have led to an explosion of interest in customer engagement. Assaad, \& Gomez, (2011) defined "Social networking at a high level is described as the convergence of technologies that allow individuals to easily communicate, share information, and form new communities online." The most well-known social software applications are weblogs, wikis, social networking sites, and instant messaging. Classification of social media involves grouping applications currently subsumed under the generalized term into more specific categories by characteristics, i.e., collaborative projects, blogs, content communities, social networking sites, virtual game worlds, and virtual social worlds. Liking or sharing social media messages can increase the effects of popular cohesion and message diffusion. The communicators can embrace social media tools to manage risk better.

\section{SOCIAL MEDIA: SITES}

Today, one's daily routine is well neigh incomplete without a minimal visit to social media websites. For personal or professional or entertainment, we use one/two/ more of the most globally known social media, including Facebook, Tumblr, Twitter, Flickr, LinkedIn, YouTube, Instagram, Shots, Reddit, and others. Social Media are networking websites that aim at encouraging and strengthening the relationship among individuals, groups, and companies (Kelley et al., 2012; Tripathi \& Verma, 2018). Thus, Blogs, YouTube, Myspace, Facebook, Snapchat, and Pinterest are all covered within the social media definition (Loanas \& Stoica, 2014). They help us communicate using different sorts of messaging of videos, audio, pictures, and text. These sites can carry structured, unstructured, and semi-structured data with robust analytical tools. Communication can be of any type, relating to transportation, security, governance, election, entertainment, movies, games, tourism, shopping, plantation, education, healthcare, pharmaceutical, manufacturing, products, and their feedbacks and much more news. Table 2 in the next page describes in detail the most frequently used social networking sites. It represents the parent companies and sets up timings along with founders, objectives, and language. 
Table 2. Top Social Media Sites

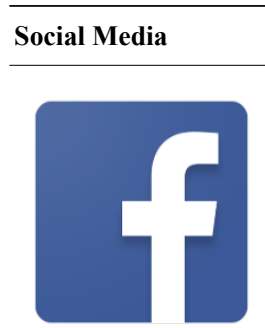

Facebook is a social networking (SNS) site, based in California, United States of America.

www.facebook.com

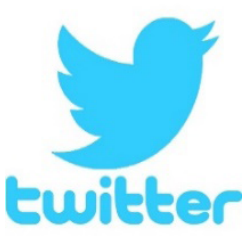

www. twitter.com

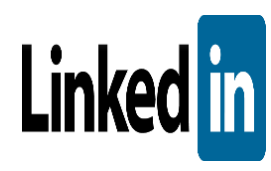

www.linkedin.com

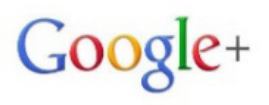

Get way into what you love plus.google.com
Twitter is a Social Networking Site (SNS). Twitter users can send messages with a restriction of 140 characters.

LinkedIn is developed for online recruitments for business organizations. Many global companies are also using it for professional networking.

Google Corporation runs Google Plus. Google'+ also using online socializing services.
Started in 2006. The Head

Quarter is mounted in

San Francisco, United States (USA)

The company started in December, 2002. The company main office is located at California (USA)

Founded on June 28, 2011 California, United States (USA)
Jack Dorsey, Evan Williams, Noah Glass, Biz Stone

Reid Hoffman, Konstantin Guericke, Jean-Luc Vaillant, Allen Blue, Eric Ly

Google, Larry Page - (Cofounder) Sergey Brin - (Cofounder)

Language

Cambridge, Massachusetts,

$$
\text { (USA) }
$$

\author{
Java, Ruby, Scala, \\ JavaScript
}

\author{
PHP (as HHVM) \\ and D language \\ Eduardo Saveri \\ drew McCollum, \\ Chris Hughes \\ Mark Zuckerberg, \\ Dustin Moskovitz,

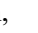




\section{SOCIAL MEDIA: APPLICATIONS}

Kaplan, \& Haenlein, (2011) report says, "Jeffrey Rayport introduced the term viral marketing in 1996." After that, various authors have discussed viral marketing in the literature for over 15 years. The available literature reveals that social networks have many practical benefits for business organizations. However, on the other side, direct marketing is facing many challenges. As part of a company's marketing strategy, social media sites have increased significantly in the past few years. In today's marketing, promotion has become one of the most critical factors in conducting business. Many large corporations for marketing and advertising have adopted social media such as Facebook and Twitter. However, Bakeman \& Hanson, (2012) expressed, "Small businesses have been slow to follow suit, typically because of limited resources to devote to mastering this new marketing media." Social media is a hybrid element of the promotion mix because, in a traditional sense, it enables companies to talk to their customers. Given the unprecedented reach of social media, firms are increasingly relying on it as a channel for marketing communication. The emergence of Internetbased social media has made it possible for one person to communicate with hundreds or even thousands of other people about products and the companies that provide them. Hence, prospective customers can connect with the company representatives on various social media platforms for better communication; for example: LinkedIn.

The concept of social media is at the top of the agenda for many business executives today. Decision-makers and consultants try to identify ways in which firms can make profitable use of applications such as Wikipedia, LinkedIn, YouTube, Facebook, Myspace, Second Life, Twitter, and several others. Twitter is a service that individuals and businesses in many industries embrace, with the growth of social networking sites and its ability to deliver real-time information to thousands of people instantly. Twitter social media is a microblogging platform developed in 2006. Twitter activities and sales performances of five companies from the Fortune 500 companies and its competitors were analyzed. Chadwick Martin Bailey and iModerate Research Technologies found that consumers are $67 \%$ more likely to buy from the brands they follow on Twitter and $51 \%$ more likely to buy from a brand they follow on Facebook. Mashable source indicates social media phenomena highly influence the audience. Given the fast growth of social media software and social networking, companies are being forced to increase online activities in their traditional Customer Relationship Management (CRM) systems. Return on Investment (ROI) has also become the holy objective of social media for multinational companies. Few authors have indicated that social media marketing strategies help generate funds for social causes (Tripathi \& Verma, 2016). Social media is a preferred mode of communication for building the relationship between marketers and consumers. Thus, social media platforms are nurturing relationships with customers.

Even though social media has been recognized as the most potentially powerful medium in business practice, there is a lack of understanding of why people use social media and how they perceive social media marketing messages. The researchers are trying to understand social media popularity and how marketers are influential on social media, especially in the hotel industry. Social networking sites heavily affect the users' online activities, and their effect on the tourism sector is crucial. In travel and tourism, past research has focused attention on the socio-psychological aspects of social media use. Not surprisingly, travel-related virtual communities have attracted the attention of tourism researchers early on (Kim et al., 2004; Wang \& Fesenmaier, 2003; Wang et al., 2002). Social media has opened new platforms for librarians and information professionals to market library and information services. Social media is playing an increasingly important role as information 
sources for travelers also. In Pakistan, marketing on social networks is not taken seriously. Though some companies have shown interest and created their presence, yet they are not seriously focused. Before implementing social media into business, marketers calculate the return on investment on social media marketing. Marketers are concerned about budget allocation because of the uncertainty of return on investment on social media. In the year 2013, U.S. companies spent $\$ 5.1$ billion on social media advertising. Still, a recent Gallup survey revealed that these advertisements did not influence the buying decisions of most of the U.S. consumers. An important aspect is the lower costs associated with social media marketing. Promoting brands and other marketing activities through social media does not cost the firm as much as conventional hoardings and TV advertisements, besides being far more convenient. Many professionals understand they should be doing more with social media but are unsure where to begin. However, the more widespread and increased use of social media has gained attention in all organizations to a new level. The authors; Saravanakumar \& SuganthaLakshmi, (2012) explored "Several corporate houses are formulating plans and strategies to harness maximum benefit from the digital freedom associated with social media-based marketing." Today, social media is among the 'best openings available' to a brand for connecting with prospective consumers across the globe. Both traditional and social media communications have a significant impact on brand equity. Online customers use social media to give reviews about products and services $24 / 7$. That is why social media is an unparalleled platform for communication. Hence, companies can place brand posts containing videos, messages, quizzes, information, and other material on these brand fan pages. Consumers are utilizing platforms such as content sharing sites, blogs, social networking, and wikis - to create, modify, share, and discuss Internet content.

\section{SOCIAL MEDIA: TECHNOLOGIES}

Social Media technology is supposed to be created by its users (Selwyn, 2012). Social Media technologies have profoundly touched humanity. The McKinsey study revealed that there were as many as ten ways that the social media technologies were adding value to the human society; this included co-creating products, demand forecasting, distributing business processes, conducting market research, marketing communications, lead generation, social commerce, customer care, collaboration, and matching talents to roles. Dumbrell \& Steele (2014) stated, "These social technologies have several characteristics that may suit information access and informal knowledge management by older adults, and there is a rapid uptake of these technologies by this demographic." Social media technologies have been seen to contain a plethora of information, covering many topic areas. Previously it has been identified that there is a large volume of quality health information on these platforms and an extensive range of condition-specific categories that this information falls under (Dumbrell \& Steele, 2013). Besides, as per Trainor (2012); "social media technologies are helping more incredible firm performance through the CRM module." Social media has four major potential strengths: collaboration, participation, empowerment, and time. In terms of time, social media technologies allow users to immediately publish information in near-real-time (Bertot et al., 2010; Magro, 2012). Magro et al. (2009) indicated, "Social media is considered a part of the Web 2.0 movement, characterized by user-generated content, online identity creation, and relational networking." Tim O'Reilly coined the term Web 2.0 in 2004, but the label remains challenging to define acceptably. The first feature, micro-content, suggests that authors create small chunks of content, with each chunk conveying a primary idea or concept. A second essential component to Web 2.0 is what is referred to as "social software." (Alexander, 2006). Murugesan, (2007) propounded, "Web 2.0 is also called the Wisdom Web, People-centric Web, Participative Web, and Read/Write 
Web. Web 2.0 harnesses the Web more interactively and collaboratively, emphasizing peers' social interaction and collective intelligence, and presents new opportunities for leveraging the Web and engaging its users more effectively." Social media is effortless and accessible from everywhere in the world. Following are some of the new technologies that are likely to make a difference over the coming years and make our lives easier (Mike Laurie, 2009). (1) Arduino is a small circuit board commonly used to prototype electronics. Its low cost and ease of implementation have meant that this little device is now leading a hobbyist revolution connecting real-life objects to social networks like Twitter. For instance, it has allowed us to create a device attached to a chair that tweets at the presence of noxious natural gasses (2) RFID and Transponders technologies using in our day-to-day life (3) Geomagnetic sensors show the absolute orientation by detecting the direction of the earth's magnetic field lines. The geomagnetic sensor in the widely used smartphone has already become popular as a navigation aid (Nakajima, \& Haruyama, 2012) (4) Optical Pattern Recognition \& Augmented Reality (5) OpenID, OAuth, and the Identity Graph: OpenID is an open authentication protocol that lets users use a single set of login credentials for every site they visit. It is already in use at hundreds of smaller websites, and large sites like Facebook are starting to accept OpenID accounts. Once a user is authenticated, a second open protocol called OAuth will help them share personal data with other sites being used (6) Mind Reading: The ability to read the mind of other individuals to infer their mental state by interpreting subtle social cues is indispensable in human social interaction. The neuropeptide oxytocin plays a central role in social approach behavior in nonhuman mammals. The ability to tweet what one is thinking without pulling out one's phone, typing the message, and hitting send can be overwhelming. One may imagine being able to think 'Facebook' and getting an automatic overview of a friend's activity stream immediately, without punching any buttons on the keypad (7) Natural Language Processing (NLP): NLP is the study of mathematical and computational modeling of various aspects of language and the development of a wide range of systems (Joshi, 1991). Like Optical Pattern Recognition, NLP seeks to categorize and understand what humans understand.

\section{SOCIAL MEDIA: THEORIES}

\subsection{Integration-Theory}

Literature suggests that social media such as YouTube, Twitter blogs, and Facebook can enhance public relations exercise. These media facilitate two-way communication between an organization and its general consumers/customers. According to the social media integration theory model described by Sinclaire \& Vogus (2011), social media platforms effectively provide the exposure, feedback, connection, and sharing of information (Alomayri, 2016). According to Hogan and Quan-Haase (2010), "social media's social affordance means that people are employing these tools to interact, share information, communicate, and develop perceptions about their social environment." Hyder (2017) has researched various marketing theories, including the "Social Media Integration Theory Model" derived by Garcia I. (2010). However, he says that such models do not provide step-by-step guidelines to develop a social media marketing plan. The Social Media-Integration-Theory-Model is supported by various research discussions (Garcia, 2011; Ibrahim, 2013; Webb, \& Roberts, 2016). Figure 2 below denotes the Social Media-Integration-Theory-Model. This social media model consists of four communication network components (1) Connecting, (2) Sharing, (3) Feedback, and (4) Exposure. The theory says that it has ample future scope compared to the traditional communication methods. The communication method is not restricted to simplex, that is, one-way communication. It has the potential of a mix of simplex, duplex and full-duplex channel that helps high-speed communication. 
Garcia (2010) revealed "social media" integration is an interactive process. It enables same-level information exchange among the audience and the brand. It creates long-lasting communication and improves brand engagement. In this model, social media interaction through the connected Social Networking sites like Facebook, Twitter,

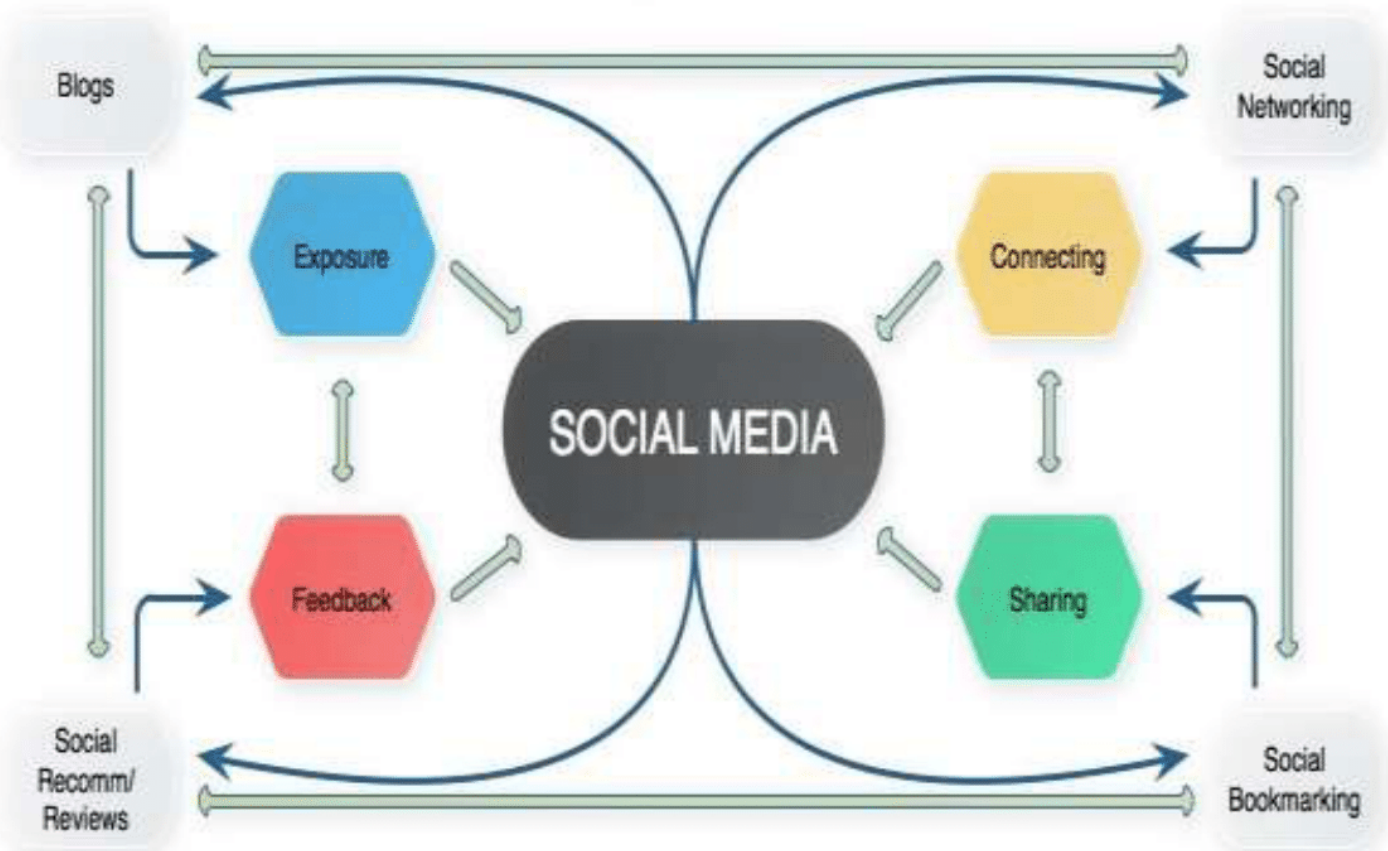

Figure 2. Social Media-Integration-Theory-Model (Garcia I., 2010)

LinkedIn, and Myspace - users carry out social bookmarking by placing the blog's content into an active social media eco-system. This digital content is then shared and distributed to the social network peers through common groups, associations, professions, habits, and interests. Post this; social networking platforms help connect with the public and improve the engagement approach caused by the "two-way street" simultaneous interaction process called the full-duplex communication mode. Further, Garcia (2010) also indicates social recommendation; reviews are the driving forces of engagement. The online conversation on social networks results in giving valuable feedback or experience about the product or services. High-capacity broadband connection is needed to carry these social media data at the background level at speeds like terabytes/second - petabytes/secondzettabytes/second. Finally, these feedback reviews melt in the same process as the conceptualization of the blogging platforms. Thus, connecting with the peers on the network, giving feedback, engaging, and sharing information are included in the Social Media-Integration-Theory-Model.

\subsection{Content Theory}

To be candid, although social media was born before 2000, its communication in the world of business marketing is still a new field. Hence, academic theories related to this topic are still in the formative stage. It explains the enormous volume of time and resources that modern-day businesses 
spend on social media platforms like Facebook, Twitter, and LinkedIn to conduct research or develop social media marketing theories and lead them in the right direction. Among the prominent social media theories, there is one that was developed by JC Social Media (2014), known as the "Social Media Theory: Content." They developed a model for strategy creation. The "Social Media Theory: Content" model is built on the three contributing factors of social media, including (1) The Goals, (2) The Brand, and (3) The Audience. There are, of course, several factors determining the ways of deriving all three of these goals, branding and audience parts. Combining the goals, brand, and the audience gives rise to three other vital elements of an effective social media strategy: one's 'hit list,' what one's value-adding content looks like, and one's interaction strategy. In the social media theory - content, the interaction strategy can be a combination of particular social media goals and objectives and how it is branding the products or services in the global market. The second component is the purchasing power of product brands and their value in the audience or customer's view.

The third vital component is that the more hit creation in the hearts of the audience should match the companies' goals, as in, Management by Objectives (MBO). However, the overall social media content strategy should be a combination of Goals, Brand, and Audience. The theory is well explained and represented in Figure 3.

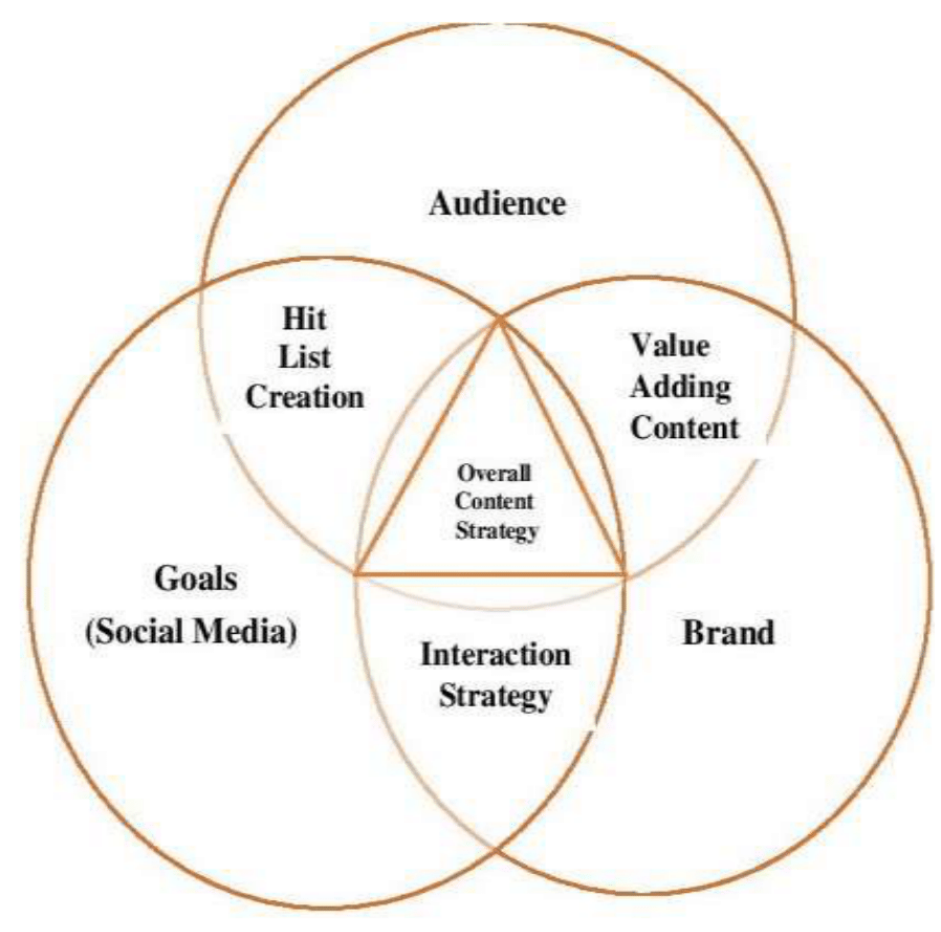

Figure 3. The Content Theory

Source: https://www.jcsocialmedia.com/social-media-theory/social-media-strategy-development/) 


\section{SOCIAL NETWORK SITES: REFERENCE ARCHITECTURE}

Following is a Social Network Site: Reference Architecture model with components in Figure 4. Danah Boyd and Nicole B. Ellison (Mike Gotta, 2008) established this model.

- Participation Models

- Website Content and Applications

- Infrastructure Services Model

- Social Presence

- Actor Profiles

- Social Graph

- Relation Controls

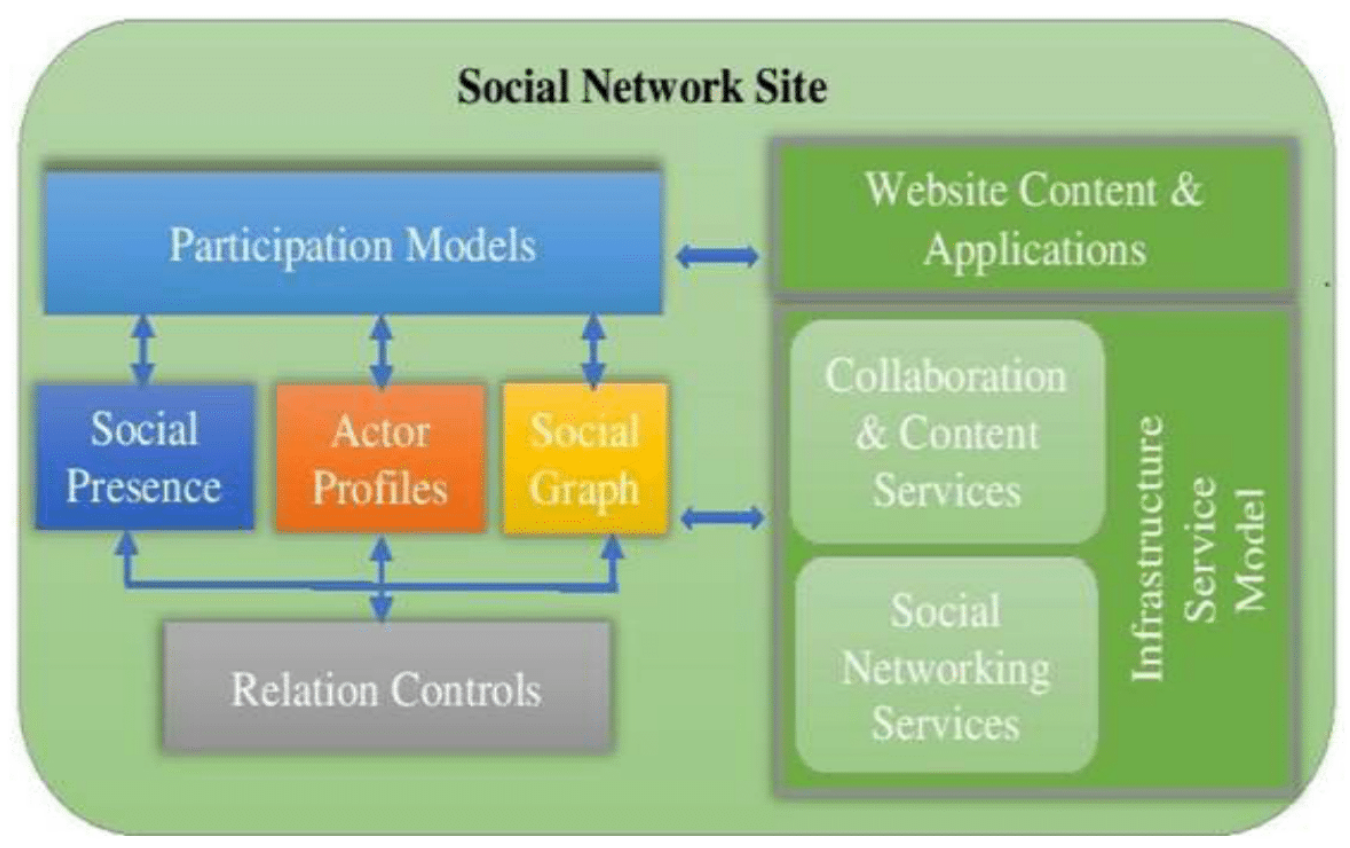

Figure 4. Social Media Sites: Reference Architecture

Source: Danah Boyd and Nicole B. Ellison (Mike Gotta, 2008)

\subsection{Participation Models}

The Participation models are developed based on Human Sociology. These models are generally used for assessing the performance of social media. From the diagram given below, it is evident that there is a two-way data flow between the components. Actor Profiles are connected to the Relation Controls because only the actor should set his privacy controls. Participation models are connected to Social Graph, Actor Profiles, and Social Presence because the performance of social networking sites is measured by considering all these profiles. There is a two-way data flow between website content and applications and infrastructure and services model because these components are responsible for the effective functioning of the entire networking site. 


\subsection{Website Content and Applications}

This component comprises all the required data and applications needed to run a social networking site, including videos, photos, and text. All the search engines like Google, AOL, Yahoo, Rediff, Mamma, etc., will help.

\subsection{Infrastructure Services Model}

The infrastructure Services Model is responsible for usability, interoperability, maintainability, and consistent corporate policy enforcement. The Infrastructure Services Model uses Social Networking Services and collaboration and content services of hardware components, including smart devices.

\subsection{Actor Profiles}

These are the profiles provided within the enclosed system, which describe the person/group.

\subsection{Social Presence}

Social Presence provides visibility of the connections between the actor and his friends to other participants of the system. It also provides access to people to navigate through these connections in all the networking sites.

\subsection{Social Graph}

Social Graph is a graph that shows the personal relations of the actor in a Social Networking site. It shows how people are mapped, how they are related in a diagram.

\subsection{Relation Control}

Relation Controls are the privacy controls given to the actors to control their visibility settings, i.e., who can view their profiles or access their connections globally.

\section{CONCLUSION}

Social media communication through social media networking sites (web 3.0) has several implications for our daily life. Their applications are not only limited to our personal blogging through videos, audios, pictures, news, and reviews but also other professional applications in disciplines like business communications, tourism guidance, medical care, disaster alerts, technology learning, operations management, recruitment, new technological information, entertainment, and others, etc. Social media is being used by rural populations and old-aged people, not being restricted to the urban youth, and is available in all predominant global languages. It is necessary to use Facebook, LinkedIn, Twitter, Myspace, and other web media applications more fruitful for unified, round-theclock communication. Being academicians, our presence in "social media" is particularly significant, as it will usher in new knowledge for users and provide more conceptual clarity. It is the technology where all ages, tribes, and categories of people using across the globe. Hence, it is the need of our 
scientific community groups should develop and scribble new manuscripts for the benefit of all societies. There are many theories, and academic literature had already poured into different forms. Such articles will help in developing the social media-related theories in a scientifically sound manner. These research scriptures will remain in the research domain as a beacon for the budding analysts. The future studies should focus on the empirical studies on this topic of Social Media/Networking in business applications.

\section{ACKNOWLEDGMENTS}

We are thankful to the FORE School of Management (New Delhi) for the infrastructural and financial support to conduct this research and scribbling this manuscript. We are also deeply thankful to all the authors who published or blogged about Social Media. These articles increased our knowledge of the topics and helped formulate ideas and develop this conceptual article innovatively.

\section{REFERENCES}

Alexander, B. (2006). Web 2.0: A new wave of innovation for teaching and learning? Educause review, 41(2), 32. Accessed dated on 12/12/2019, from the Uniform Resource Locator, https://er.educause.edu/ articles/2006/1/web-20-a-new-wave-of-innovation-for-teaching-and-learning.

Alomayri, A. S. (2016). Comparing Twitter messages between New York City and Al Riyadh municipality, and creating a social media plan for Al Riyadh municipality in Saudi Arabia. http://cardinalscholar.bsu. edu/handle/123456789/200222.

Assaad, W., \& Gómez, J. M. (2011). Social network in marketing (social media marketing) opportunities and risks. International Journal of Managing Public Sector Information and Communication Technologies, 2(1), 13.

Bakeman, M. M., \& Hanson, L. (2012). Bringing social media to small business: A role for employees and students in technology diffusion. Business Education Innovation Journal, 4(2), 106-111. Accessed dated on 12/12/2019 from the Uniform Resource Locator, http://elmstpress.com/images/BEI_Jnl_Dec_2012_ text.pdf\#page $=106$.

Bertot, J. C., Jaeger, P. T., \& Grimes, J. M. (2010). Using ICTs to create a culture of transparency E-government and social media as openness and anti-corruption tools for societies. Government information quarterly, 27(3), 264-271. https://doi.org/10.1016/j.giq.2010.03.001.

Boyd, D. M., \& Ellison, N. B. (2007). Social network sites: Definition, history, and scholarship. Journal of computer-mediated Communication, 13(1), 210-230. https://doi.org/10.1111/j.1083-6101.2007.00393.x

Bulut, I., \& Mandaric, M. (2012). Researching the role of social media marketing in contemporary business practices. Application of Neuroscientific Concept in Defining an Effective Marketing Communication Strategy, 1185.

DesAutels, P. (2011). UGIS: Understanding the nature of user-generated information systems. Business Horizons, 54(3), 185-192. Accessed dated on 12/1/2019, from URL https://doi.org/10.1016/j. bushor.2010.12.003.

Dumbrell, D., \& Steele, R. (2013, January). Twitter and health in the Australian context: What types of information are health-related organizations tweeting?. In 2013 46th Hawaii International Conference on System Sciences (pp. 2666-2675). IEEE. DOI: 10.1109/HICSS.2013.578. 
Garcia, I. (2010). Social media-integration-theory-model like it? [Web log post]. Accessed on 1/2/2017.

Garcia, I. (2011). Social media-integration: theory-model. Social Media Today. Accessed on 30/3/2020.

Hogan, B., \& Quan-Haase, A. (2010). Persistence and change in social media. Bulletin of Science, Technology \& Society, 30(5), 309-315. DOI: 10.1177/0270467610380012.

Hyder, A. (2017). Social Media Marketing Channels for Kotka-Hamina.

Ibrahim, B. H. (2013). Nigerians usage of facebook during 2012 Occupy Nigeria protests: between networked and real public spheres. Science Journal of Researcher, 5(7), 55-64.

Ioanăs, E., \& Stoica, I. (2014). Social media and its impact on consumers behavior. International Journal of Economic Practices and Theories, 4(2), 295-303.

JC Social Media (2014). URL accessed from https://www.jcsocialmedia.com/social-media-theory/.

Joshi, A. K. (1991). Natural language processing. Science, 253(5025), 1242-1249. Accessed form the URL https://science.sciencemag.org/content/253/5025/1242, DOI: 10.1126/science.253.5025.1242.

Kaplan, A. M., \& Haenlein, M. (2010). Users of the world, unite! The challenges and opportunities of Social Media. Business horizons, 53(1), 59-68. https://doi.org/10.1016/j.bushor.2009.09.003.

Kaplan, A. M., \& Haenlein, M. (2011). The early bird catches the news: Nine things you should know about micro-blogging. Business horizons, 54(2), 105-113. https://doi.org/10.1016/j.bushor.2010.09.004.

Kelly, L. Jugenheimer, D \& Sheehan, K (2012). Advertising Media Planning. USA: M.E. Sharpe Inc.

Khan, G. F. (2015). Seven Layers of Social Media Analytics: Mining Business Insights from Social Media Text. Actions, Networks, Hyperlinks, Apps, Search Engine, and Location Data.

Kietzmann, J. H., Hermkens, K., McCarthy, I. P., \& Silvestre, B. S. (2011). Social media? Get serious! Understanding the functional building blocks of social media. Business horizons, 54(3), 241-251. https:// doi.org/10.1016/j.bushor.2011.01.005.

Kim, W. G., Lee, C., \& Hiemstra, S. J. (2004). Effects of an online virtual community on customer loyalty and travel product purchases. Tourism management, 25(3), 343-355. https://doi.org/10.1016/S02615177(03)00142-0.

Magro, M. J., Ryan, S. D., Sharp, J. H., \& Ryan, K. A. (2009). Using social networking for educational and cultural adaptation: An exploratory study. AMCIS 2009 proceedings, 528. Accessed dated on 4/5/2018 from the URL https://aisel.aisnet.org/cgi/viewcontent.cgi?article=1549\&context=amcis2009.

Magro, M. J. (2012). A review of social media use in e-government. Administrative Sciences, 2(2), 148-161. https://www.mdpi.com/2076-3387/2/2/148, DOI: 10.3390/admsci2020148.

Milanovic, R. (2015). The world's 21 most important social media sites and apps in 2015. Social Media Today.

Mike Gotta (2008). Collaborative Thinking. Perceptions on collaboration and social networking. http:// mikeg.typepad.com/perceptions/2008/07/next-document-r.html.

Mike Laurie (2009). 7 Technologies Shaping the Future of Social Media, Accessed on from the http:// mashable.com/2009/06/01/social-media-future-tech/\#BsTgM9xt.iq3.

Murugesan, S. (2007). Understanding Web 2.0. IT professional, 9(4), 34-41. Accessed from the URL https:// ieeexplore.ieee.org/abstract/document/4287373, DOI: 10.1109/MITP.2007.78.

Nakajima, M., \& Haruyama, S. (2012, August). Indoor navigation system for visually impaired people using visible light communication and compensated geomagnetic sensing. In 2012 1st IEEE International Conference on Communications in China (ICCC) (pp. 524-529). IEEE. DOI: 10.1109/ ICCChina.2012.6356940. 
Peters, K., Chen, Y., Kaplan, A. M., Ognibeni, B., \& Pauwels, K. (2013). Social media metrics-A framework and guidelines for managing social media. Journal of interactive marketing, 27(4), 281298. Accessed dated on 1/2/2017 from the URL https://www.sciencedirect.com/science/article/abs/pii/ S109499681300042X. DOI:10.1016/j.intmar.2013.09.007.

Samant, S. M., \& Sangle, S. (2016). A selected literature review on the changing role of stakeholders as value creators. World Journal of Science, Technology and Sustainable Development. DOI: 10.1108/ WJSTSD-01-2016-0002, From the URL https://www.emerald.com/insight/content/doi/10.1108/ WJSTSD-01-2016-0002/full/html.

Saravanakumar, M. and SuganthaLakshmi, T. (2012). "Social Media Marketing”, Life Science Journal, 9(4): 44-55.

Selwyn, N. (2012). Social media in higher education. The Europa world of learning, 1, 1-10. Accessed dated on 2/4/2017 from the Universal Resource Locator https://pdfs.semanticscholar.org/e661/ e51ce237ded12da9b1ef126a842663b8fb53.pdf.

Sinclaire, J. K., \& Vogus, C. E. (2011). Adoption of social networking sites: an exploratory adaptive structuration perspective for global organizations. Information Technology and Management, 12(4), 293314, DOI:10.1007/s10799-011-0086-5, https://link.springer.com/article/10.1007/s10799-011-0086-5.

Trainor, K. J. (2012). Relating social media technologies to performance: A capabilities-based perspective. Journal of Personal Selling \& Sales Management, 32(3), 317-331.https://www.tandfonline.com/doi/ abs/10.2753/PSS0885-3134320303. DOI: 10.2753/PSS0885-3134320303.

Tripathi, S., \& Verma, S. (2018). Social media, an emerging platform for relationship building: A study of engagement with nongovernment organizations in India. International Journal of Nonprofit and Voluntary Sector Marketing, 23(1), e1589.

Tripathi, S., \& Verma, S. (2016). Determinants of Relationship Building on Social Media: An Empirical Study on NGOs in India.

Tripathi, S., \& Verma, S. (2017). A Retrospective Study of Supporter Engagement with Non-Government Organizations on Social Media. IOSR Journal of Business and Management, 19 (7), 43-50.

Tripathi, S., \& Verma, S. (2017). Analysing Technological Dimensions for Engagement with NGOs on Social Media. The International Journal Research Publications Research Journal of Social Science and Management, 7 (4), 174-184.

Trusov, M., Bucklin, R. E., \& Pauwels, K. (2009). Effects of word-of-mouth versus traditional marketing: findings from an internet social networking site. Journal of marketing, 73(5), 90-102. https://journals. sagepub.com/doi/abs/10.1509/jmkg.73.5.90, DOI:10.1509/jmkg.73.5.90.

Webb, S. H., \& Roberts, S. J. (2016). Communication and social media approaches in small businesses. Journal of Marketing Development and Competitiveness, 10(1).DOI: 10.33423/jmdc.v10i1.1857. Accessed dated on 23/3/2017 from the URL https://articlegateway.com/index.php/JMDC/article/ view/1857,

Wang, Y., Yu, Q., \& Fesenmaier, D. R. (2002). Defining the virtual tourist community: implications for tourism marketing. Tourism management, 23(4), 407-417. DOI: 10.1016/S0261-5177(01)000930. Accessed dated on 2/2/2018 from the URL, https://www.sciencedirect.com/science/article/abs/pii/ S0261517701000930.

Wang, Y., \& Fesenmaier, D. R. (2003). Assessing motivation of contribution in online communities: An empirical investigation of an online travel community. Electronic markets, 13(1), 33-45.

Wattal, S., Schuff, D., Mandviwalla, M., \& Williams, C. B. (2010). Web 2.0 and politics: the 2008 US presidential election and an e-politics research agenda. MIS quarterly, 669-688. From the URL, https:// 